\title{
МОРАЛЬНО-ПРАВОВЫЕ АСПЕКТЫ ОГРАНИЧЕНИЯ ГРАЖДАНСКИХ ПРАВ И СВОБОД ЧЕЛОВЕКА ПРИ COVID-19
}

\author{
АЛИЕВ Ильхам Малик оглы - ведущий научный сотрудник Института \\ Права и Прав Человека НАНА, доктор философии по праву

\begin{abstract}
В представленной статье прежде всего отмечается, ито правовые ограничения являются мерами, направленнъими на реализацию позитивньгх прав и свобод человека и гражданина, исключаюшими нелегитимнъе способъ их реализаиии. Утверждается, что чаще всего права индивида нарушаются государством, и поэтому тезис о приоритете прав и свобод личности должен означать, в первую очередь, верховенство прав индивида над государством.
\end{abstract}

Далее автором рассматриваются принятьле в челях борьбъ с новой коронавирусной инфекиией (COVID-19) в Азербайджане, ограничительнъе и запретительные мерь и их соответствие действующему законодательству Республики, а также то, что в законодательстве Азербайджана отсутствует такое легальное понятие, как «особъй карантинныий режим». Напоминается, ито категория «самоизолячия» вошла в юридический оборот только в прошлом году, однако юридически она не закреплена на уровне законодательньих актов, что приводит к неоднозначному ее толкованию. При этом, эббективность правовых норм, их исполнение во многом обусловливается тем, насколько они соответствуют требованиям морали.

В итоге исследования отмечается моральная обязанность государства не допускать того, чтобы серъезнъий кризис медичинского характера перерастал в кризис с правами человека только потому, что надлежащее здравоохранение может бъть недоступнъм для населения. Государство должно принимать меры в интересах того, итобы обеспечивать каждому человеку наличие и экономическую доступность медицинской помощи и лечения.

Ключевъе слова: права и свободъ, государство, правовъие ограничения, Международнылй пакт, гражданин, индивидуальная свобода.

Права и свободы человека - неотъемлемое, неотчуждаемое достижение человеческого рода. Какие бы события и действия ни совершались в этом мире, какие бы научные открытия ни входили в него, они не должны негативно влиять на положение человека, его права и свободы. В этом состоит суть человеческого измерения всех процессов мирового и национального развития, выдвигающего ценностный ориентир, позволяющих дать оценку всех процессов, - права человека $(1,2-3)$.

Ограничения, в свою очередь, есть меры, направленные на реализацию позитивных прав и свобод человека и гражданина, исключающие нелегитимные способы их реализации. Ограничения есть форма реализации позитивных действий и исключение действий негативных. Ограничения можно классифицировать на экономические, политические, социальные, правовые. Нас интересуют, конечно же, правовые ограничения, и поэтому, исходя из формы права, закрепляющей ограничение можно выделять конституционно-правовые ограничения, ограничения, устанавливаемые законами, 


\section{Теорія, історія держави і права, конституційне право}

подзаконными актами, судебными решениями.

Государство, принимая на себя обязанность обеспечения закрепленных ею в конституции прав и свобод человека и гражданина, в то же время на основании закона и норм международного права, в интересах национальной безопасности, охраны общественного порядка прибегает к их ограничению и даже отчуждению. Особенный общественный резонанс вызывают случаи правомерности ограничения таких лично и социально-значимых прав и свобод человека, как право на свободу и неприкосновенность, свободы мысли, слова, совести, передвижения. Как отмечают некоторые ученые, все основные права, даже если они являются производными от естественных прав человека, имеют предпосылкой своего существования, с одной стороны, наличие именно государства, которое их гарантирует и защищает, а с другой - противостояние государства основным правам, и здесь уже возникают вопросы морального обоснования подобного противостояния. Необходимость учета международно-правовых актов по поводу ограничения прав человека и гражданина отмечает, например российская исследовательница В.М. Малиновская (2, 181-182). На ее взгляд, государству важно вводить на законодательном уровне те ограничения, которые будут отвечать установленным международным стандартам и насущным потребностям общественных отношений, которые развиваются.

Выдвижение прав индивида над правом государства - одно из великих достижений человеческой культуры. Утверждение о приоритете прав человека над коллективными правами, в частности правом на самоопределение, сделано из лучших побуждений. История Советского Союза убедительно показала, к чему приводит пренебрежение правами и свободами индивида, их принесение в жертву якобы интересам коллектива (в нашем случае - главным образом класса, партии или государства). Результат - диктатура и отсутствие каких-либо прав и свобод даже у «господствующего», т.е. рабочего класса. В Германии, например, упор на права и исключительность арий- ской расы, ликвидация не только прав, но и самих представителей «неполноценных» наций привели к диктатуре и порабощению всего немецкого народа. Эти примеры, пожалуй, - крайности, но, тем не менее, или благодаря этому они весьма наглядны. Проанализировав соотношение индивидуальных и коллективных прав, Р.А. Мюллерсон совершенно правильно отмечал, что обеспечение прав и свобод каждого человека необходимо ставить, если не выше, то, во всяком случае, на один уровень с правами любых других социальных общностей, будь то государство, класс, нация или даже народ. Ибо под флагом примата прав и интересов последних, как далее он заключает, нередко совершались тяжкие преступления не только против отдельных людей, но и против целых народов $(3,43)$. Чаще всего права индивида нарушаются государством и поэтому тезис о приоритете прав и свобод личности должен означать в первую очередь верховенство прав индивида над государством, т.е. права и свободы личности ставят пределы для государственной власти. В каком-то смысле это может означать торжество моральных принципов, когда слабая сторона, в лице прав индивида, не поглощается сильной стороной, т.е. государством.

Произошедшая весной 2020 года пандемия новой коронавирусной инфекции COVID-19, проявления которой продолжаются и в настоящее время, стала серьезнейшим вызовом не только для экономических и политических систем, но и для механизмов реализации и защиты основных прав и свобод человека, активно формировавшихся в последние десятилетия. В числе стран, столкнувшихся с указанными вызовами, оказалась и Азербайджанская Республика.

Существует мнение, что наши общества и системы здравоохранения не были готовы к пандемии COVID-19, и это подняло моральные и медико-правовые проблемы. Ученые поясняют, что на постсоветском пространстве очевидный конфликт между обязанностью врачей заботиться о пациентах и их правами защищать свое здоровье, свои семьи и близких. Тем не менее, заражение медицинских работников является неотъемлемым профессиональным риском 
для медицинских работников, и Уголовный кодекс наказывает специалистов, связанных с охраной здоровья населения, которые «не в состоянии оказать помощь» нуждающемуся лицу, но в то же время и для этих работников должны быть созданы надежные гарантии для того, чтобы они могли защитить себя» $(4,14)$. В целом же, по всему миру женщины составляют $70 \%$ работников здравоохранения и социальной защиты, то есть именно они находятся на передовой борьбы с пандемией и в сфере здравоохранении имеют повышенный риск заражения вирусом. Возникающее в связи с этим в обществе настороженное отношение к медикам-женщинам чревато социальным отчуждением или стигматизацией в ситуации, когда они и без того вынуждены уделять повышенное внимание собственному здоровью и здоровью своих близких. Это может создавать проблемы, например, когда возникает необходимость организовать или сохранить присмотр за детьми, пока женщина выполняет свой врачебный долг.

В целях борьбы с новой коронавирусной инфекцией в большинстве стран были приняты ограничительные и запретительные меры, которые формально не отвечали признакам чрезвычайной ситуации, но содержали предписания, характерные для них. Например, формально в и ряде других стран были приняты меры, которые характеризуются как режим повышенной готовности, а также иные ограничительные меры санитарно-эпидемиологического характера. Такие меры не соответствовали режиму чрезвычайной ситуации, который не был введен, но ориентировали государственные органы и население на соответствующее этому режиму поведение. Эти меры не содержали прямого запрета или ограничения прав и свобод, содержащихся в Законе Азербайджанской Республики «О чрезвычайной ситуации», но накладывали ряд ограничений на права населения и налагают на него дополнительные обязанности (5). При этом одновременно был введен ряд дополнительных полномочий организационно-распорядительного и запретительного характера для органов власти. Особый карантинный режим (ОКР) у нас в стране введен в соответствии со статьей 25 Закона $\mathrm{AP}$ «O санитарно-эпидемиологическом благополучии» (6). Интересно, что Закон был принят в 1992 году и, несмотря на внесение в него некоторых изменений, все еще находится в силе. В соответствии со статьей 25 этого Закона, «При угрозе возникновения или распространения инфекционных, паразитарных, неинфекционных массовых заболеваний правительство Азербайджанской Республики, главные государственные санитарные врачи в пределах своей компетенции вводят в установленном порядке на соответствующих территориях или объектах особые условия и режимы труда, учебы, передвижения, перевозок, а при необходимости проводят работы по обеззараживанию, дезинфекции, дезинсекции, дератизации и дезактивации, направленные на предупреждение возникновения и распространения этих заболеваний и их ликвидацию» (6).

ОКР, вступивший в силу 24 марта, позже был ужесточен Постановлениями Кабинета министров AP № 120 от 30 марта 2020 года и № 124 от 2 апреля 2020 года. Как видно из статьи закона, приводимой в качестве правовой основы особого карантинного режима, этот режим может вводиться «на соответствующих территориях или объектах». Однако, указанный ОКР, как известно введен по всей стране, что несколько не совпадает с буквой упомянутого закона. С другой стороны, налагаемые ОКР ограничения, например ограничение свободы передвижения, и возлагаемые на людей дополнительные обязанности наводят на определенные сомнения по поводу их соответствия как Конституции Азербайджана, так и конвенциям, подписанным нашей страной.

Наиболее показательными стали практически в полном объеме выполняемые населением меры соблюдения режима самоизоляции, контролируемые посредством новых коммуникационных технологий, в частности, специальных приложений на мобильных телефонах, переход на удаленную работу, запрет на поездки не только в другие регионы, но и в рамках конкретного населенного пункта, соблюдение «масочного режима» и социальной дистанции и т.п. один аспект, на который хотелось бы обратить 


\section{Теорія, історія держави і права, конституційне право}

внимание - это понятие «самоизоляция». Сама категория «самоизоляция» вошла в юридический оборот только в прошлом году, однако юридически она не закреплена на уровне законодательных актов, что приводит к неоднозначному ее толкованию, как со стороны государственных органов, так и со стороны граждан. Полагаем, что данное понятие целесообразно определить законодательно и предусмотреть юридические механизмы самоизоляции, а также последствия ее несоблюдения. Хотелось бы отметить, что данное понятие не определено и в законодательстве иностранных государств.

Рассматривая ситуацию в конституционном измерении, можно утверждать, что здоровье человека является естественным условием осуществления провозглашенных Конституцией АР прав и свобод личности, а стало быть, естественным условием достойной жизни. Другими словами, реализация предусмотренного положениями ст. 41 (ч. 1) Конституции АР права на охрану здоровья и медицинскую помощь находится в самой непосредственной взаимосвязи с такой конституционной ценностью, как достоинство личности (ст. 16 и 46 Конституции АР) (7). Государство, в силу положений ст. 16 и 46 Конституции АР, обязано охранять достоинство личности во всех сферах, чем утверждается приоритет личности и ее прав, в то время как на законодателя возлагается обязанность соотносить свою деятельность с принципом признания достоинства личности. Как известно, посредством Конституции государство взяло на себя обязательство признавать, соблюдать и защищать от любых незаконных вмешательств и ограничений права и свободы человека и гражданина.

В соответствии со статьей 12 Конституции Азербайджанской Республики 1995 года, обеспечение прав и свобод человека и гражданина, достойного уровня жизни гражданам Азербайджанской Республики высшая цель государства. Согласно статье 71, соблюдать и защищать права и свободы человека и гражданина, закрепленные в Конституции, является обязанностью органов законодательной, исполнительной и судебной властей (7). Никто не может ограни- чить осуществление прав и свобод человека и гражданина. Права и свободы каждого ограничиваются основаниями, установленными в настоящей Конституции и законах, а также правами и свободами других. Данные гарантии также относятся к праву полной охраны здоровья, поскольку право на охрану здоровья стало неотъемлемой частью комплекса прав человека.

Во многих странах право на охрану здоровья стало частью внутригосударственного права, закреплено в основных правовых актах, предоставляются широкие возможности для реализации данного права в соответствии с международно-признанными стандартами. Всеобщая декларация прав человека (принята Генеральной Ассамблеей ООН 10.12.1948) закрепила положение о том, что при осуществлении своих прав и свобод каждый человек должен подвергаться только таким ограничениям, какие установлены законом исключительно с целью обеспечения должного признания и уважения прав и свобод других и удовлетворения справедливых требований морали, общественного порядка и общего благосостояния в демократическом обществе. Конституция Азербайджанской Республики, ориентируясь на международные стандарты в области прав человека, допускает в определенных случаях их ограничение (8).

Кроме того, в статье 2 Протокола № 4 к «Европейской конвенции о защите прав человека и основных свобод» также предусмотрено, как «...право на свободу передвижения и свободу выбора местожительства», так и ограничения, «...которые предусмотрены законом и необходимы в демократическом обществе в интересах государственной безопасности или общественного спокойствия, для поддержания общественного порядка, предотвращения преступлений, охраны здоровья или нравственности или для защиты прав и свобод других лиц» (9). Правда, здесь «охрана здоровья» может выглядеть как законная цель, но трудно утверждать, что ограничения «предусмотрены законом». В законодательстве Азербайджана нет такого легального понятия, как «особый карантинный режим». По своим признакам и создаваемым им особым 
правовым последствиям этот режим, скоpeе, похож на чрезвычайное положение (которое никто и не объявлял - курсив автора). А в период объявления чрезвычайного положения предусматриваются широкие гарантии соблюдения имущественных и социальных прав всех юридических и физических лиц. Не исключено, что власть предержащие желают избежать выполнения этой обязанности. В медицинской науке XX век связывается с углублением понимания сущности здоровья и болезни, успехами биологии, микробиологии, вирусологии, иммунологии, изучения нервной и эндокринной регуляции, наследственности и генетики $(10,15)$.

Пожилые люди подвержены более высокому риску развития побочных эффектов от лекарственных препаратов, а также ятрогенных заболеваний. Сочетание множественных мелких расстройств может оказывать на пожилых людей значительное кумулятивное психологическое воздействие. Расстройства, обусловленные острым заболеванием, могут развиваться на фоне имеющихся физических или психических нарушений, а также сочетаться с материальными трудностями и социальной изоляцией $(11,32)$. В домах престарелых и других учреждениях с большим числом пожилых людей политика допуска посетителей должна строиться на балансе интересов защиты подверженного риску контингента с их потребностями в общении с семьей и человеческих контактах. Пожилые люди действительно относятся к группе повышенного риска, однако тотальные ограничения не учитывают медицинских рекомендаций и потребностей этих пожилых людей.

Государство также должно обеспечивать, чтобы финансовые соображения не ограничивали доступ людей к тестированию, профилактике и лечению COVID-19. В Азербайджане многие говорят, что изза своего материального положения избегают обращаться к врачу или покупать назначенные лекарства, что приводит к ухудшению их состояния. В условиях эпидемии уклонение от обращения к врачу наносит ущерб не только самому человеку, но и окружающим, поскольку чревато распространением вируса. Оба вышеуказанных момента (потребности пожилых людей и доступность лечения в зависимости от материального положения человека), напрямую имеют отношение к морали и нравственности. Правовые нормы служат и должны служить проводниками морали, закреплять и защищать нравственные устои общества. И эффективность права во многом зависит от того, насколько полно, адекватно оно выражает эти требования. Сила законов во много раз увеличивается, если они опираются не только на власть (особый аппарат), но и на мораль. В свою очередь, действие морали, как и других социальных норм, в немалой степени зависит от четко функционирующей юридической системы. Ведь все эти регуляторы составляют единое нормативное поле.

Для лиц, считающих себя высокоморальными, или для лиц, признающих моральные нормы «выше» закона, соблюдение норм юридических должно являться естественным и обыденным. Об этом, в частности, очень хорошо сказал выдающийся немецкий философ Г.Ф. Гегель, на наш взгляд, раз и навсегда поставив точку в вопросе о взаимоотношении между правом и моралью: «...Право и мораль отличаются друг от друга. Нечто вполне позволительное с точки зрения права может быть чем-то таким, что моралью запрещается. Право, например, разрешает мне распоряжаться своим имуществом, совершенно не определяя пределов этого распоряжения, и только мораль содержит определения, которые его ограничивают. Может казаться, будто мораль разрешает много такого, чего не разрешает право. Однако мораль требует не только соблюдения права по отношению к другим, а, напротив того, соединяет с правом умонастроение, состоящее в том, чтобы уважать право ради права. Мораль требует даже, чтобы, прежде всего, было соблюдено право и лишь после того, как оно исчерпано, вступали бы в действие моральные определения» (12).

Әффективность правовых норм, их исполнение во многом обусловливается тем, насколько они соответствуют требованиям 


\section{Теорія, історія держави і права, конституційне право}

морали. Чтобы правовые нормы работали, они, по крайней мере, не должны противоречить правилам морали. Право в целом должно соответствовать моральным взглядам общества. Мораль - необходимая принадлежность всякого общества, ее значение неуклонно возрастает, причем должно постоянно усиливаться взаимодействие правовых и моральных факторов в жизни общества, их взаимная поддержка, а не поглощение права моралью; чем лучше будет налажено это взаимодействие, тем успешнее будет движение общества по пути прогресса. Право и мораль находятся в тесном единстве и взаимодействии. С помощью норм права государство добивается утверждения прогрессивных норм морали, которые, в свою очередь, способствуют укреплению морального авторитета права, воспринимаемого как социальная ценность всего общества. Но при всем этом, нельзя упускать из виду опасность освобождения от моральных принципов самого государства.

Подытоживая вышеизложенное, отметим моральную обязанность государства не допускать того, чтобы серьезный кризис медицинского характера перерастал в кризис с правами человека только потому, что надлежащее здравоохранение может быть недоступным для населения. Аюбое правительство должно принимать меры в интересах того, чтобы обеспечивать каждому человеку наличие и экономическую доступность медицинской помощи и лечения.

В правовой плоскости государство должно принимать законодательные меры в интересах того, чтобы здравоохранение было доступным для всех, в том числе по цене, без дискриминации и при соблюдении медицинской этики и уважении культурных особенностей, и чтобы услуги здравоохранения были надлежащего качества. Также государству следует воздерживаться от тотальных и избыточно широких ограничений свободы передвижения и личной свободы и прибегать к общеобязательным ограничениям в период пандемии только в тех случаях, когда это оправдано и необходимо с научной точки зрения и когда возможно обеспечение наличия механизмов поддержки социально уязвимых слоев населения.
Морально обоснованными меры добровольной самоизоляции будут лишь в сочетании с просвещением и всеобщей доступностью лечения, что будет способствовать сотрудничеству с государством и вызывать закономерное доверие со стороны общества.

\section{\итература}

1. Права человека: итоги века, тенденции, перспективы / Под ред. Е.А. Аукашевой. - М.: Норма, 2003. - 448 с.

2. Стрекозов В.В. Конституционное право России. Учебник. - Москва: Юрайт, 2018. - 256 c.

3. Мюллерсон Р.А. Права человека: идеи, нормы, реальность. М.: Юридическая литература, 1991. - 160 с.

4. Семина Т.В., Тыртышный А.А., Образование и право - № 7 - 2020, с.11-20

5. Закон Азербайджанской Республики «О чрезвычайном положении» от 8 июня 2004-го года. http://www.e-qanun.az/alpidata/ framework/data/6/c f 6193.htm

6. Закон Азербайджанской Республики «О санитарно-эпидемиологическом благополучии» http://files.preslib.az/projects/azereco/ru/eco_m4_2.pdf

7. Конституция Азербайджанской Республики от 12 ноября 1995 года. Баку: Ганун, 2016

8. Всеобщая Декларация прав человека 1948 года http://www.un.org/russian/ documen/declarat/declhr.htm (дата обращения: 17.02.2021).

9. Протокол № 4 к «Европейской конвенции о защите прав человека и основных свобод" http://hrlibrary.umn.edu/russian/euro/ $\underline{\text { Rz23prot4.html }}$

10. Медицинское право. Курс лекций / Под ред. А.Н. Плеханова. Новосибирск: Изд-во СибАГС, 2015. - 167 с.

11. Касаева Ж.Ә. Социологический анализ медико-социальной работы с пожилыми людьми: Дис. ... канд. соц. наук. Волгоград, 2008. - 134 с.

12. Георг Вильгельм Фридрих Гегель «Философская пропедевтика» // http://sophia. nau.edu.ua/library/text/geg fpr.html 


\section{Aliyev Ilham Malik oghlu MORAL AND LEGAL ASPECTS OF THE RESTRICTION OF GIVIL RIGHTS AND HUMAN FREEDOMS IN THE TIME OF COVID-19}

The proposed article, first of all, notes that legal restrictions are measures aimed at the realization of positive human and civil rights and freedoms, excluding illegitimate ways of their implementation. It is argued that most often the rights of the individual are violated by the state and therefore the thesis about the priority of the rights and freedoms of the individual first of all, should mean, the supremacy of the rights of the individual over the state.

Further, the author analyses the restrictive and prohibitive measures adopted in order to combat the new coronavirus infection (COVID-19) in Azerbaijan, and their compliance with the current legislation of the Republic, as well as the fact that there is no such legal concept as a "special quarantine regime" in the legislation of Azerbaijan. It is pointed out that the category of "self-isolation" entered the legal space only last year, but it is not legally enshrined at the level of legislative acts, which leads to its ambiguous interpretation. At the same time, the effectiveness of legal norms, their implementation is largely determined by the extent to which they meet the requirements of morality.

The study summarizes the moral obligation of the state to prevent a serious medical crisis from escalating into a human rights crisis only because that adequate health care may not be available to the population.

The state should take measures to ensure every person the availability and affordability of medical care and treatment.

Keywords: rights and freedoms, state, legal restrictions, International Covenant, citizen, individual freedom. 